\title{
Meteorological drivers of ablation processes on a cold glacier in the semi-arid Andes of Chile
}

\author{
S. MacDonell ${ }^{1}$, C. Kinnard ${ }^{1}$, T. Mölg ${ }^{2}$, L. Nicholson ${ }^{3}$, and J. Abermann ${ }^{1}$ \\ ${ }^{1}$ Centro de Estudios Avanzados en Zonas Áridas, La Serena, Chile \\ ${ }^{2}$ Chair of Climatology, Technische Universität Berlin, Berlin, Germany \\ ${ }^{3}$ Centre for Climate and Cryosphere, University of Innsbruck, Innsbruck, Austria
}

Correspondence to: S. MacDonell (shelley.macdonell@gmail.com)

Received: 27 March 2013 - Published in The Cryosphere Discuss.: 29 April 2013

Revised: 31 July 2013 - Accepted: 7 August 2013 - Published: 25 September 2013

\begin{abstract}
Meteorological and surface change measurements collected during a $2.5 \mathrm{yr}$ period are used to calculate surface mass and energy balances at $5324 \mathrm{~m}$ a.s.l. on Guanaco Glacier, a cold-based glacier in the semi-arid Andes of Chile. Meteorological conditions are marked by extremely low vapour pressures (annual mean of $1.1 \mathrm{hPa}$ ), strong winds (annual mean of $10 \mathrm{~m} \mathrm{~s}^{-1}$ ), shortwave radiation receipt persistently close to the theoretical site maximum during cloudfree days (mean annual $295 \mathrm{~W} \mathrm{~m}^{-2}$; summer hourly maximum $1354 \mathrm{~W} \mathrm{~m}^{-2}$ ) and low precipitation rates (mean annual $45 \mathrm{~mm}$ w.e.). Snowfall occurs sporadically throughout the year and is related to frontal events in the winter and convective storms during the summer months. Net shortwave radiation provides the greatest source of energy to the glacier surface, and net longwave radiation dominates energy losses. The turbulent latent heat flux is always negative, which means that the surface is always losing mass via sublimation, which is the main form of ablation at the site. Sublimation rates are most strongly correlated with net shortwave radiation, incoming shortwave radiation, albedo and vapour pressure. Low glacier surface temperatures restrict melting for much of the period, however episodic melting occurs during the austral summer, when warm, humid, calm and high pressure conditions restrict sublimation and make more energy available for melting. Low accumulation (131 mm w.e. over the period) and relatively high ablation (1435 mm w.e.) means that mass change over the period was negative $(-1304 \mathrm{~mm}$ w.e.), which continued the negative trend recorded in the region over the last few decades.
\end{abstract}

\section{Introduction}

In the semi-arid Andes of Chile $\left(26-32^{\circ} \mathrm{S}\right)$, snow- and ice melt is thought to be the primary contributor to streamflow, and generally acts to alleviate drought problems in otherwise dry spring and summer seasons (Favier et al., 2009). Snowmelt is thought to be the dominant contributor to the watershed, however conclusive source comparisons are currently lacking, largely due to the difficulty of accurately measuring and modelling ablation processes in this area (Gascoin et al., 2012). Past studies in the region focusing on cryospheric contributions to streamflow have taken a watershed approach to the problem, and have used black-box approaches to give first estimations of the relative contributions from snowpacks and cold-based glaciers (Favier et al., 2009; Gascoin et al., 2011). These studies suggest that snow- and glacier melt contribute to the bulk of the runoff, but as the methods used in these studies do not capture the physical processes of ablation at a sufficiently high temporal or spatial resolution, it remains difficult to link ablation processes and melt water production with atmospheric conditions.

In the semi-arid Andes, ablation consists of both sublimation and melting, in contrast to low-humidity, lowtemperature environments such as on the plateau on the East Antarctic Ice Sheet, where only sublimation occurs (Bintanja, 1999) and to temperate environments where melt dominates, and sublimation is unimportant (e.g. Giesen et al., 2008; Gillet and Cullen, 2011). Energy balance modelling on the cold-based glaciers of the semi-arid Andes therefore requires correct treatment of sublimation and subsurface heat flux in order to correctly partition ablation into melting 
(e.g. Hoffman et al., 2008; Mölg et al., 2008), which can contribute to runoff, and sublimation, which does not.

To date there have been no published energy balance studies on glaciers in the semi-arid Andes of Chile and so here we focus on understanding ablation processes on glacier surfaces, using energy balance modelling and on-site measurements to identify the triggers for melt in this extremely dry environment. In order to do this, we focus on understanding the connections between meteorological conditions and the surface energy balance on a penitente-free surface on the Guanaco Glacier, in the upper Huasco Valley in the semi-arid Andes of Chile.

\section{Site description}

Glaciers exist in south-facing, lee slope locations above $4500 \mathrm{~m}$ a.s.l. (Nicholson et al., 2010), and cover up to $11 \%$ of the land surface (Gascoin et al., 2011) of the upper Huasco catchments $\left(29^{\circ} \mathrm{S}, 70^{\circ} \mathrm{W},>4000 \mathrm{~m}\right.$ above sea level (a.s.l.); Fig. 1). Glaciers are restricted in size due to low precipitation rates, and high ablation rates caused by high levels of shortwave radiation receipt and low humidity (Ginot et al., 2002; Kull et al., 2002; Nicholson et al., 2010; Gascoin et al., 2012).

Guanaco Glacier (Fig. 1) is a relatively large glacier for the region $\left(1.8 \mathrm{~km}^{2}\right)$ that straddles the Chile-Argentina divide $\left(29.3^{\circ} \mathrm{S}, 70.0^{\circ} \mathrm{W}, 4990-5350 \mathrm{~m}\right.$ a.s.l.) (Nicholson et al., 2010). Between 1955/1956 and 2007 the glacier shrank by $0.33 \mathrm{~km}^{2}$, which equates to $15 \pm 4 \%$, and measurements of the glacier mass balance since 2003/04 have been consistently negative, which may be at least partially due to low precipitation rates (Rabatel et al., 2011). The glacier is planar in its highest reaches, but is predominantly terraced $(<1 \mathrm{~m}$ in height), and penitentes can be found in the south-western region of the glacier near the discharge outlet. This study considers conditions at a point on a planar surface in the uppermost section of the glacier (star in Fig. 1). Here wind speeds are relatively strong throughout the year (average $8.5 \mathrm{~m} \mathrm{~s}^{-1}$ during the study period), and hourly mean temperatures vary between $-25^{\circ} \mathrm{C}$ in winter to $5^{\circ} \mathrm{C}$ in summer. Relatively high wind speeds coupled with low snow retention experienced on the upper section of the glacier (Gascoin et al., 2012) are unfavourable for the development of penitentes (Corripio and Purves, 2005). Sublimation is expected to dominate the ablation regime, because of the aridity of the atmosphere, high wind speeds and low air temperatures (e.g. Bintanja and van den Broeke, 1995; Wagnon et al., 2003; Mölg and Hardy, 2004; Hoffman et al., 2008), however, melting has been observed periodically at the surface during the summer months.

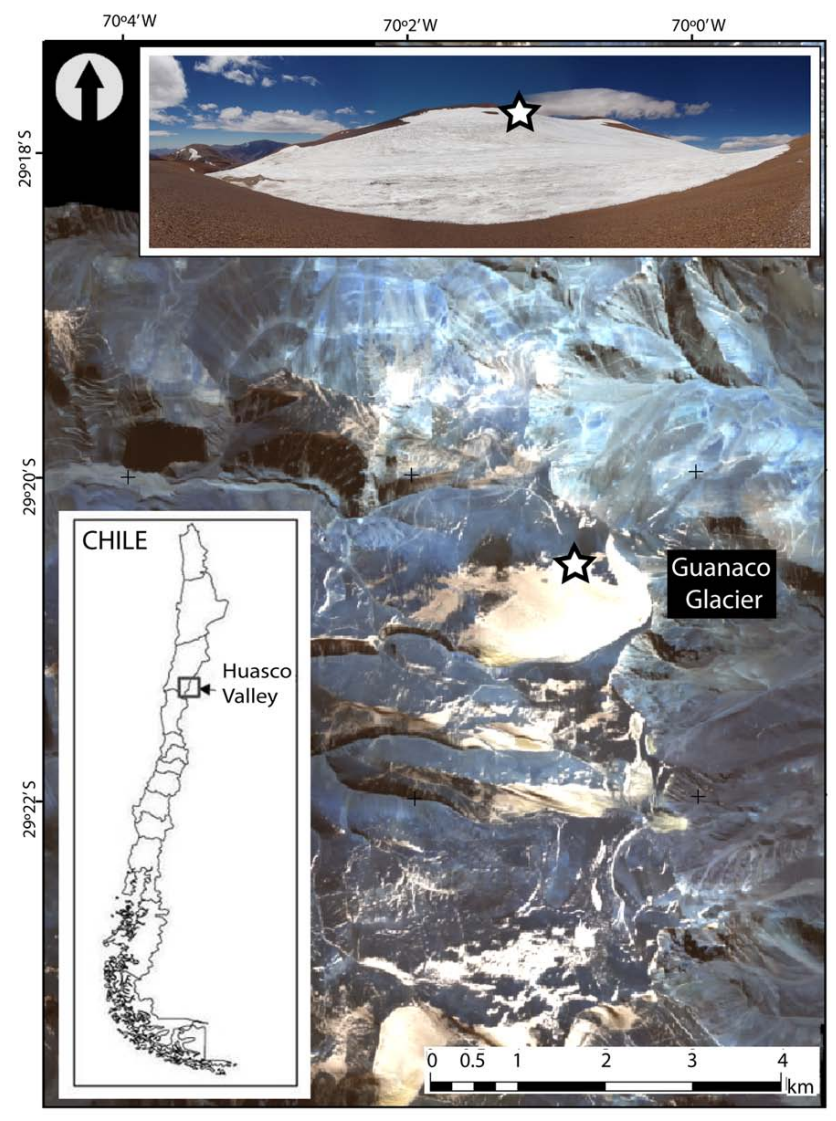

Fig. 1. Ikonos image of the upper Huasco Valley (2005), showing the location of Guanaco Glacier and its automatic weather station (star). The insets show the location of the Huasco Valley in Chile, and an oblique photograph of the Guanaco Glacier taken from its southern-eastern side, looking up the glacier.

\section{Methods}

\subsection{Meteorological measurements}

The Guanaco Glacier Automatic Weather Station (G-AWS) is located at $29.34^{\circ} \mathrm{S}, 70.01^{\circ} \mathrm{W}, 5324 \mathrm{~m}$ a.s.l. on a southeast-facing surface with a local slope of $7.5^{\circ}$ (star in Fig. 1). The station was originally installed in December 2007, and has operated continuously since 9 October 2008. Measurements include incoming and outgoing shortwave and longwave radiation, naturally ventilated, shielded air temperature and relative humidity, wind speed and direction, and surface height change (Table 1). Additionally, barometric pressure measurements are available from an offglacier AWS $\left(29.30^{\circ} \mathrm{S}, 70.00^{\circ} \mathrm{W}, 4933 \mathrm{~m}\right.$ a.s.l.), which are elevation-adjusted to G-AWS for use in the mass balance model. All measurements are sampled every $10 \mathrm{~s}$, and are stored as hourly means on a Campbell Scientific CR1000 datalogger. This study examines data from 1 November 200830 April 2011, which corresponds to $2.5 \mathrm{yr}$ of data covering 
Table 1. Details of the instruments and the annual mean conditions at this site (calculated using data between 1 November 2008-31 October 2010). All measurements were at G-AWS on the glacier surface except for air pressure, which is from a station $3 \mathrm{~km}$ away at an elevation of 4927 m a.s.l.

\begin{tabular}{|c|c|c|c|c|}
\hline $\begin{array}{l}\text { Measured } \\
\text { Quantity }\end{array}$ & Instrument & $\begin{array}{l}\text { Measurement } \\
\text { Range }\end{array}$ & $\begin{array}{l}\text { Nominal } \\
\text { Accuracy }\end{array}$ & $\begin{array}{l}\text { Annual } \\
\text { Mean }\end{array}$ \\
\hline Air temperature & Vaisala HMP45C & -39.2 to $+60^{\circ} \mathrm{C}$ & $\begin{array}{l}0.2^{\circ} \mathrm{C}\left(\text { at } 20^{\circ} \mathrm{C}\right) \\
0.5^{\circ} \mathrm{C}\left(\text { at }-39.2^{\circ} \mathrm{C}\right)\end{array}$ & $-10^{\circ} \mathrm{C}$ \\
\hline Relative humidity & Vaisala HMP45C & 0.8 to $100 \%$ & $\begin{array}{l}2 \%(0 \text { to } 90 \%) \\
3 \%(90 \text { to } 100 \%)\end{array}$ & $\begin{array}{l}40 \% \\
\text { (vapour pressure: } 1.1 \mathrm{hPa} \text { ) }\end{array}$ \\
\hline Wind speed & Young 05103 & 1 to $60 \mathrm{~m} \mathrm{~s}^{-1}$ & $0.3 \mathrm{~m} \mathrm{~s}^{-1}$ & $10 \mathrm{~ms}^{-1}$ \\
\hline Solar radiation & Kipp \& Zonen CNR1 & 0 to $2000 \mathrm{~W} \mathrm{~m}^{-2}$ & $10 \%$ for daily sums & $\begin{array}{l}\text { SWI: } 295 \mathrm{~W} \mathrm{~m}^{-2} \\
\text { SWO: } 139 \mathrm{~W} \mathrm{~m}^{-2} \\
\text { Albedo: } 0.55\end{array}$ \\
\hline Longwave radiation & Kipp \& Zonen CNR1 & -250 to $+250 \mathrm{~W} \mathrm{~m}^{-2}$ & $10 \%$ for daily sums & 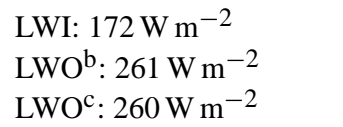 \\
\hline Surface height & Campbell SR50 & 0.5 to $10 \mathrm{~m}$ & $0.01 \mathrm{~m}$ or $0.4 \%$ & \\
\hline Air pressure & Met-One 090D & $500-1100 \mathrm{hPa}$ & $0.35 \mathrm{hPa}\left(\right.$ at $\left.20^{\circ} \mathrm{C}\right)$ & $516 \mathrm{hPa}^{\mathrm{a}}$ \\
\hline
\end{tabular}

${ }^{\text {a }}$ Values are elevation corrected from a land-based station. This represents the mean value at G-AWS.

b Uncorrected values.

c Values corrected for window heating offset.

three "ablation" seasons (austral summer), and two "accumulation" seasons (austral winter).

Careful quality control of data from stations in harsh environments is mandatory before data use (e.g. van den Broeke et al., 2004). The largest errors were expected to be due to riming and solar heating of the instruments. However comparison of incoming and outgoing shortwave radiation indicated that the measurements were not adversely affected by snow cover or riming of the upper sensor, as expected for high-altitude, dry locations (Mölg et al., 2009), and so no corrections were made. Due to power constraints, none of the sensors on the G-AWS are artificially ventilated, which means that the data may be susceptible to errors due to solar heating during periods of high solar radiation and low wind speeds (Georges and Kaser, 2002). However, as the mean wind speed over the period is $9.2 \mathrm{~m} \mathrm{~s}^{-1}$, and only $3.5 \%$ of the hourly values have wind speeds of $<2 \mathrm{~m} \mathrm{~s}^{-1}$, problems due to sensor heating are likely to be minimal. Following this rationale, air temperature measurements were not corrected for artificial heating. However, analysis of the outgoing longwave radiation measurements showed that there were several hours when measured glacier surface temperature rose above $0^{\circ} \mathrm{C}$, pointing to a significant window heating offset effect (Obleitner and de Wolde, 1999). The manufacturer reports a maximum window heating offset of $25 \mathrm{~W} \mathrm{~m}^{-2}$ per $1000 \mathrm{~W} \mathrm{~m}^{-2}$ of shortwave radiation hitting the pyrgeometer (Kipp \& Zonen, 2002). However field performance testing by Michel et al. (2008) showed that sensor performance was better than stated, and recommended subtracting $15 \mathrm{~W} \mathrm{~m}^{-2}$ per $1000 \mathrm{~W} \mathrm{~m}^{-2}$ of shortwave radiation. Corrections were made to both incoming and outgoing longwave radiation measure- ments, respectively. The effect of correcting surface temperature on the energy balance is discussed in Sect. 4.3.

Relative humidity and air temperature measurements were used to calculate vapour pressure. Water and ice saturation vapour pressure was calculated using the Magnus Teten equation over ice (Murray, 1967) for air temperatures less than $0{ }^{\circ} \mathrm{C}$, and the Sonntag equation over water (Sonntag, 1990) for temperatures greater than $0^{\circ} \mathrm{C}$. Finally, the surface change measurements were smoothed using a spline function robust to outliers to remove noise from the dataset. From the smoothed surface change measurements, the solid precipitation in the mass balance model were calculated using a fresh snow density of $60 \mathrm{~kg} \mathrm{~m}^{-3}$ (Cuffey and Paterson, 2010).

\subsection{Mass balance modelling}

The specific mass balance $(b)$ of a glacier refers to the difference between accumulation $(c)$ and ablation $(a)$ per unit time and area and can be computed at local or glacier scales. The model used in this study calculates the mass balance according to Mölg et al. (2009):

$b=c_{\mathrm{sp}}+\frac{\mathrm{QM}}{L_{\mathrm{M}}}+\frac{\mathrm{QL}}{L_{\mathrm{S}}}+c_{\mathrm{en}}$,

where $c_{\mathrm{sp}}$ is the sum of solid precipitation; $\mathrm{QM}$ is the latent energy flux of melting; QL is the turbulent latent heat flux; $L_{\mathrm{M}}$ and $L_{\mathrm{S}}$ are the latent heat of melting and sublimation, respectively; and $c_{\mathrm{en}}$ is englacial accumulation by refreezing of meltwater in snow or at the interface between ice and snow. The input for the $c_{\mathrm{sp}}$ is calculated from surface change measurements, $L_{\mathrm{M}}$ and $L_{\mathrm{S}}$ are known values, and QM, QL and $c_{\text {en }}$ are calculated during the energy balance modelling. 
Sign convention for mass and energy transfer is positive for surface gains and negative for surface losses. The energy balance at the glacier surface is obtained in the model using

$$
R+\mathrm{QS}+\mathrm{QL}+\mathrm{QP}+\mathrm{QG}=F,
$$

where $R$ is the net radiation; QS is the turbulent sensible heat flux; QP is the heat flux supplied by precipitation; and QG is the subsurface heat flux (Mölg et al., 2008). The QG can be further separated into the conductive heat flux in the subsurface (QC), and the energy flux from shortwave radiation penetrating through the subsurface (QPS) (Bintanja and van den Broeke, 1995; Mölg et al., 2009). $F$ is the resultant energy flux at the surface. If the surface temperature is at the melting point $\left(0^{\circ} \mathrm{C}\right)$, and $F$ is positive on the right-hand side of Eq. (2), then $F$ represents the energy available for melt, or QM. In this study, QP is ignored because all of the precipitation falls as snow and precipitation intensity is low, which means that heat addition due to precipitation is likely to be negligible. The energy balance model used in this study has been described in detail in Mölg et al. (2008, 2009), but the specific application of the model will be outlined here. In this study, the model is run and validated for a point on the glacier surface at an hourly interval. We note that this study only calculates ablation processes operating at the ice surface, not subsurface melt within ice explicitly, and so the amount of potential runoff from the site is likely to be underestimated (Hoffman et al., 2008).

The net radiation is calculated as four separate components directly from measurements. Outgoing longwave radiation is used to calculate surface temperature using the StefanBoltzman law, assuming surface emissivity of 1 .

The turbulent sensible and latent heat fluxes are calculated using the 'bulk' method outlined in Mölg and Hardy (2004), in which measurements of air and surface temperature, relative humidity, and wind speed are used to estimate conditions at the glacier surface according to neutral logarithmic gradient profiles, along with surface roughness lengths for momentum $\left(z_{0} \mathrm{~m}\right)$ and heat/vapour $\left(z_{0} \mathrm{~h}\right)$. A correction term accounts for the stability of the boundary layer based on the Richardson number. The values of $z_{0 \mathrm{~m}}$ and $z_{0} \mathrm{~h}$ vary according to surface type, as outlined in Mölg et al. (2009). We use values of $z_{0 \mathrm{~m}}=2.0 \mathrm{~mm}$ and $z_{0 \mathrm{~h}}=0.20 \mathrm{~mm}$ for an ice surface; and $z_{0 \mathrm{~m}}=z_{0 \mathrm{~h}}=0.1 \mathrm{~mm}$ for a fresh snow surface, which increases linearly to $z_{0 \mathrm{~m}}=z_{0 \mathrm{~h}}=4 \mathrm{~mm}$ for aged snow (Mölg et al., 2009). The values of $z_{0 \mathrm{~m}}$ and $z_{0 \mathrm{~h}}$ for an ice surface are from unpublished short-term eddy covariance measurements taken $20 \mathrm{~m}$ from the G-AWS during March 2010, and are in the range of roughness lengths expected in environments where sublimation dominates (e.g. Cullen et al., 2007; Hoffman et al., 2008; MacDonell et al., 2012). As no penitentes have been observed at the G-AWS location, no values for penitentes were included.

Within the model, the englacial temperature profile is calculated using the thermodynamic equation, and includes energy release from QPS and englacial refreezing in the snow- pack (Mölg et al., 2008, 2009). The calculation of QPS uses coefficients from Bintanja and van den Broeke (1995) for the attenuation with depth, and following the energy conservation requirement, the flux at the surface is negative. The subsurface model in this study uses 14 vertical layers with boundaries at: $0.0,0.09,0.18,0.3,0.4,0.5,0.6,0.8$, $1.0,3.0,6.0,9.0,12.0$, and $15.0 \mathrm{~m}$ depth. The temperature at $15.0 \mathrm{~m}$ depth is fixed at $-6.5^{\circ} \mathrm{C}$, which is a stable temperature taken from five long-line manual temperature measurements collected at Guanaco Glacier between November 2008 and April 2011. QC is then calculated from the temperature profile.

\subsection{Mass balance model evaluation}

The mass balance results were validated by comparing the modelled hourly values of surface height change with measurements made by the ultrasonic surface height sensor (SR50) at the G-AWS using the Nash-Sutcliffe similarity measure (Nash and Sutcliffe, 1970) and root mean square error calculation (RMSE). Additionally, the results, and particularly the partitioning of ablation between melting and sublimation, were qualitatively compared with lysimeter measurements.

The lysimeters consisted of an upper $10 \mathrm{~L}$ container with holes drilled into the floor of the container placed within a $20 \mathrm{~L}$ lower container of the same surface dimensions. The upper container was filled with snow, and the lysimeter was dug into the surface, so that the surface of the container was as flush with the glacier surface as practicable. The containers were weighed before and after snow was included, and then twice daily where possible. When melt occurred, the water was removed from the lower container after weighing. Lysimeter measurements were made on the surface of Guanaco Glacier four times during this study period, however only two of these datasets will be used in this study, as the others have significant errors due to precipitation events during the course of measurement. The two viable measurement periods were between 9-21 November 2008 and 13-19 April 2009. The comparison made with these measurements is only qualitative because there are not enough measurement points to enable a statistical comparison. Accuracy of this method is estimated to be $\pm 10 \%$ (Winkler et al., 2009).

\subsection{Meteorological forcing of ablation}

The meteorological controls on sublimation were investigated by correlating the daily modelled sublimation with daily averages of the main meteorological variables recorded at the AWS. The Pearson correlation coefficient $(r)$ was calculated using raw daily sublimation and meteorological data as well as detrended data, which was obtained by removing the seasonal cycle using a fitted cosine function robust to outliers. Detrending is necessary as several meteorological variables display strong seasonality (Fig. 2) that dominates the 
relationship with sublimation. As several variables have distributions that deviate from normality and also exhibit temporal autocorrelation, the statistical significance for correlation was estimated from a Monte Carlo phase permutation test. The sublimation time series was scrambled one thousand times in frequency space, by first applying the Fourier transform to the data, scrambling the phases, and then applying the inverse transformation to obtain a surrogate time series with similar statistical properties (Davison and Hinkley, 1997). Since the Fourier transform requires normal data, a square root transformation was first used to normalize the raw sublimation data. The null distribution $(r=0)$ was obtained by correlating the surrogate series with each meteorological variable. Since the correlation coefficient measures the strength of linear relationships, bivariate scatter plots were inspected to verify that no significant deviation from linearity occurred.

Since days with melt constitute rare events that are poorly suited to correlation analysis, the meteorological control on melting was examined by comparing the mean diurnal cycle of the energy balance and meteorological drivers of melt days to that for summer days without melting, and the differences were assessed using a two-tailed Monte Carlo permutation test (Davison and Hinkley, 1997). As input to this test, the mean diurnal cycle of the energy balance, modelled surface/subsurface temperatures and associated meteorological variables were calculated for all days with modelled melt ( $n=53$ days) and were compared with that for summer days without melt $(n=310$ days). Summer was defined to include all months during which melt occurred, i.e. December to March. The daily cycle was calculated between 20:00 $\mathrm{h}$ the previous day to 20:00 $\mathrm{h}$ of the current day in order to examine preconditioning effects during the night prior to melting. Summer days $(n=363)$ were sampled randomly without replacement $(n=53)$ and the difference between the mean diurnal cycle for sampled days and that of the remaining days $(n=310)$ was calculated. The procedure was repeated 10000 times and the significance level $(p<0.05)$ was estimated from the $2.5 \%$ and $97.5 \%$ percentiles of the null distribution at each hour of the diurnal cycle.

\section{Results}

\subsection{Meteorological conditions}

Figure 2 shows the daily average meteorological conditions experienced at the Guanaco AWS site. General conditions are dictated by the annual cycle of shortwave radiation receipt. SWI shows a marked seasonal cycle (Fig. 2) that is usually in line with the theoretical receipt at the surface for clear-sky conditions (MacDonell et al., 2013). Daily deviations are caused by cloud cover, which is episodic and largely restricted to convective storm events in the summer, and frontal precipitation events during the winter (Kull et

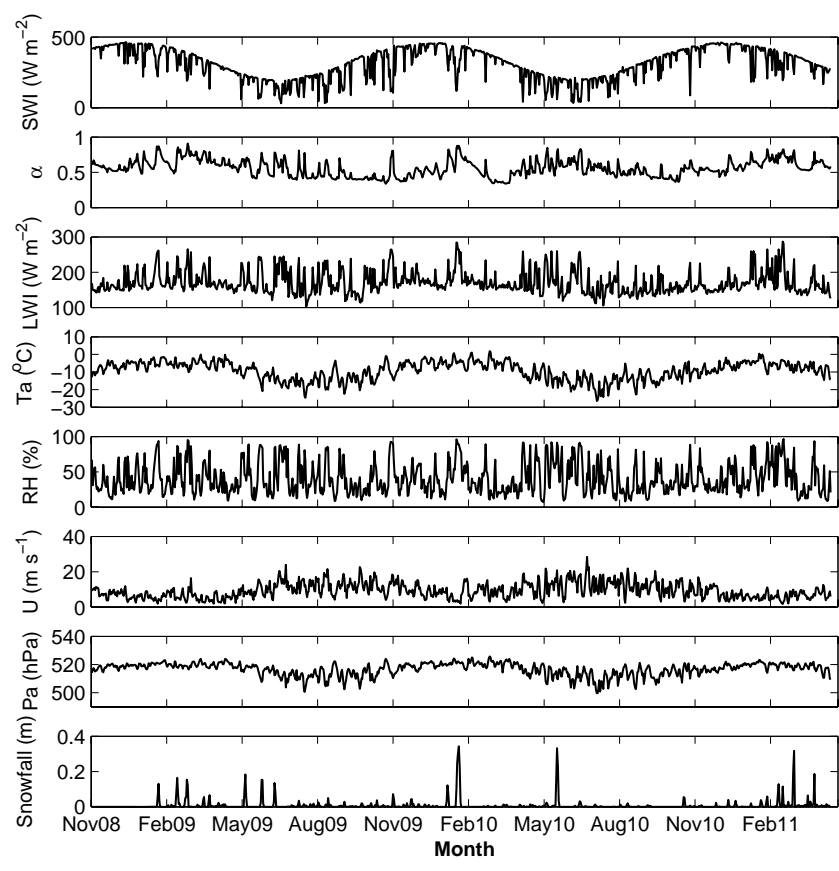

Fig. 2. Average daily incoming shortwave radiation (SWI), albedo $(\alpha)$, incoming longwave radiation (LWI), air temperature $\left(T_{\mathrm{a}}\right)$, relative humidity $(\mathrm{RH})$, wind speed $(U)$, air pressure $(\mathrm{Pa})$ and snowfall measured at the Guanaco AWS from 1 November 2008 to 30 April 2011.

al., 2002; MacDonell et al., 2013). Air temperature follows a seasonal pattern that is slightly delayed compared to the SWI cycle (Fig. 2). Higher temperatures are experienced during January and February than at the austral summer solstice, and lower temperatures are recorded in July and August than at the austral winter solstice. Mean temperature over the study period was $-9.3^{\circ} \mathrm{C}$, and hourly temperatures varied between -29.4 and $7.6^{\circ} \mathrm{C}$. Average relative humidity is $40 \%$ and relative humidity fluctuates greatly throughout the year (standard deviation $26 \%$ ), driven by cloud and precipitation events (Fig. 2; MacDonell et al., 2013). The wind speed average ( \pm standard deviation) is $9.2 \pm 4.9 \mathrm{~m} \mathrm{~s}^{-1}$ over the study period (Fig. 2). Wind speeds are slightly higher during the winter months than in the summer, however due to a large standard deviation the pattern is difficult to discern. Wind direction is almost always from the NNW. Finally, precipitation is episodic throughout the study period (Fig. 2). Snow cover is not persistent at the AWS and there is no seasonal cycle of snow depth. The role of wind erosion at the site is unknown, so it is possible that some wind scouring diminishes the snowpack immediately following deposition (Gascoin et al., 2012). 


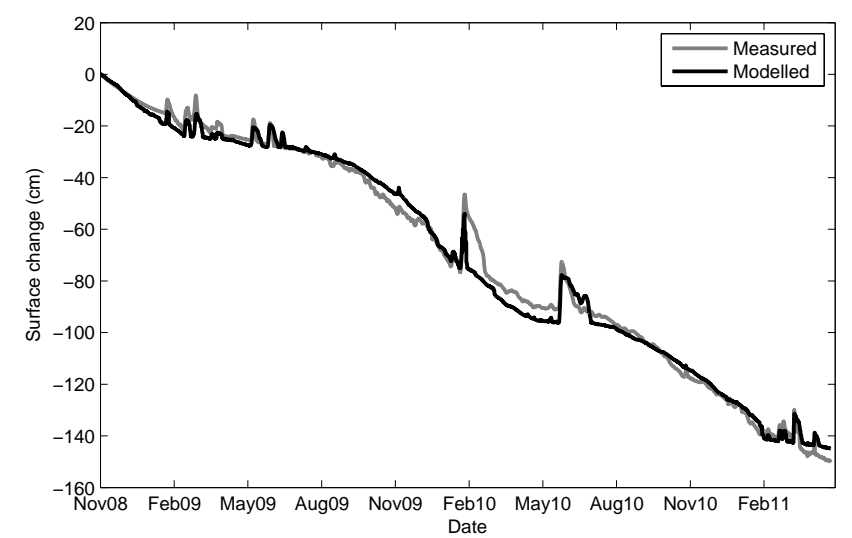

Fig. 3. Comparison of measured and modelled surface height change between 1 November 2008 and 30 April 2011. The mass balance at G-AWS was negative over the period, and the measured surface change was $-1.5 \mathrm{~m}$. The root mean square error (RMSE) of the model is $4.1 \mathrm{~cm}$ (which corresponds to a normalized RMSE of $3 \%$ ), and a Nash-Sutcliffe statistic of 0.99 .

\subsection{Mass balance model evaluation and results}

The comparison of modelled and measured surface lowering results showed that the model satisfactorily reproduced the net surface height change at this site (Fig. 3). Between 1 November 2008 to 30 April 2011, net modelled surface change was $-1.45 \mathrm{~m}$, compared with measured surface change of $-1.50 \mathrm{~m}$. The RMSE of the modelled result was $4.1 \mathrm{~mm}$ and the Nash-Sutcliffe measure was $99 \%$, indicating that model performance was very good. As most ablation events following snowfalls are relatively well reproduced, there are no detectable losses caused by wind erosion of the snowpack. This is inline with Gascoin et al. (2012) who show that glaciers in the region represent preferential snow deposition areas, and that glaciers do not lose much mass by wind transportation. The model underestimated ablation compared to the lysimeter measurements during the two lysimeter measurement periods (Table 2); however, the results are within the margin of error of the measurement technique.

The seasonal signal seen in the meteorological data (Fig. 2) is translated into seasonal fluctuations in the energy balance terms (Fig. 4). Net shortwave radiation provides the greatest energy input to the surface throughout the year, although it is significantly higher in the summer than the winter, largely due to higher SWI. Albedo does not follow a strict seasonal cycle, as variations are generally associated with episodic precipitation events (Fig. 2) and the presence of clouds (Abermann et al., 2013). Throughout the study period, net longwave radiation was the largest energy loss from the surface, because atmospheric longwave emissions are consistently very low (Fig. 2; MacDonell et al., 2013). The turbulent latent heat flux was always negative (Fig. 4) indicating that the surface was continually losing mass via sublimation. At a seasonal scale the latent heat flux followed the pattern
Table 2. Comparison between lysimeter and modelled ablation results (mm w.e. day ${ }^{-1}$ ).

\begin{tabular}{lllll}
\hline Date & Method & Melt & $\begin{array}{l}\text { Sub- } \\
\text { limation }\end{array}$ & $\begin{array}{l}\text { Net } \\
\text { ablation }\end{array}$ \\
\hline \multirow{2}{*}{ 9-21 November 2008 } & Measured & 1 & 2 & 3 \\
& Modelled & $0^{*}$ & 2 & 2 \\
13-19 April 2009 & Measured & 0 & 3 & 3 \\
& Modelled & 0 & 1 & 1 \\
\hline
\end{tabular}

* Since measured LWO during 9-21 November 2008 did not indicate melting, no meltwater flux could be modelled.

of energy supply from SWI. The subsurface heat flux was on average of smaller magnitude than the other fluxes, and fluctuated between positive and negative values throughout the study period, which basically reflects the winter and summer season, respectively. Sublimation was the main cause of ablation, and it accounted for $81 \%$ of total mass ablation over the study period (Fig. 5; Table 3). The model results indicate that generation of meltwater runoff at the site of G-AWS is restricted to the high summer period spanning DecemberMarch.

\subsection{Model sensitivity}

The mass balance model results are subject to some level of uncertainty, given errors in the measurement of meteorological variables, and the selection of model parameters. The model uncertainty was assessed using a single parameter sensitivity study whereby the model was re-run using the input data and parameters varied one at a time. Model iterations included using uncorrected longwave radiation data; modified input meteorological data spanning the precision of the respective sensors (Table 1); and modified model parameters spanning their plausible ranges (Table 4). Sublimation, melt and net ablation results were compared with the original model to assess uncertainties on mass change, and modelled surface lowering was compared with measurements to calculate the RMSE and bias on modelled results.

Using the uncorrected longwave radiation data in the model leads to a large increase in the RMSE and model bias (Table 4). Surface lowering is dramatically increased, with the total ablation increasing by $40 \%$. This is mainly due to a $195 \%$ increase in total melt, which is driven by more hours with surface temperatures at the melting point. This shows that the model is very sensitive to the values of outgoing longwave radiation used, which are used to calculate the surface temperature, and hence dictate whether or not melt is calculated. The large surface lowering RMSE confirms that the uncorrected longwave radiation measurements, which suffer from window heating effects, need to be corrected before being used to calculate surface temperature in this environment. 
Table 3. Sum of mass fluxes per season per year ( $\mathrm{mm}$ w.e.). All single terms are shown as absolute values, but the mass balance result (last line) considers the sign convention. NB: Summer refers to November-April, winter refers to May-October.

\begin{tabular}{lrrrrrr}
\hline Variable & Summer & Winter & Summer & Winter & Summer & All \\
& $08 / 09$ & 2009 & $09 / 10$ & 2010 & $10 / 11$ & \\
\hline Snowfall & 19 & 21 & 28 & 16 & 27 & 112 \\
Deposition & 4 & 4 & 3 & 5 & 3 & 19 \\
Refreezing & $<1$ & 0 & $<1$ & 0 & $<1$ & $<1$ \\
\hline Accumulation & 23 & 25 & 31 & 21 & 30 & 131 \\
\hline Melt & 42 & 0 & 141 & 0 & 88 & 271 \\
Sublimation & 225 & 192 & 339 & 186 & 223 & 1164 \\
\hline Ablation & 267 & 192 & 480 & 186 & 311 & 1435 \\
\hline Mass balance & -244 & -167 & -449 & -165 & -281 & -1304 \\
\hline
\end{tabular}

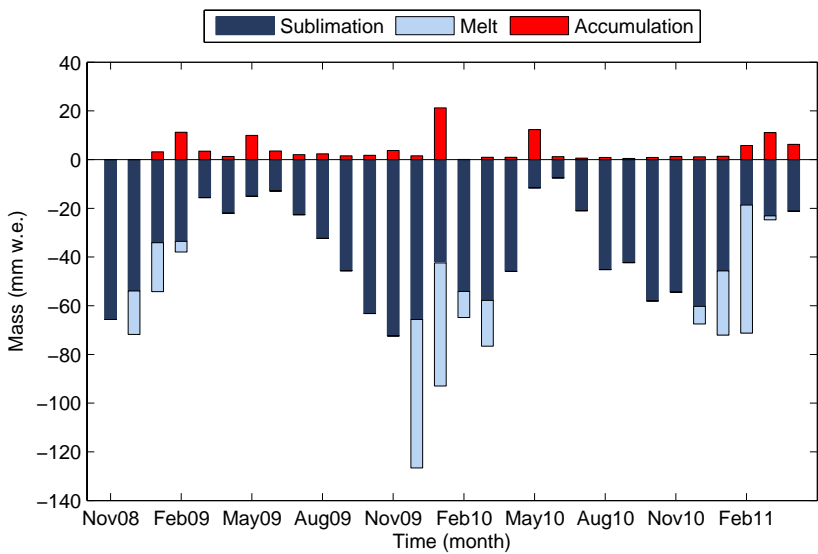

Fig. 4. Monthly totals of melt, sublimation and accumulation modelled at the G-AWS site for the period 9 October 200830 April 2011. At the G-AWS, $1164 \mathrm{~mm}$ w.e. of sublimation and $271 \mathrm{~mm}$ w.e. of melt were calculated.

All measured meteorological variables were varied according to their reported accuracy, and from this analysis, modifying incoming shortwave radiation, albedo, incoming longwave radiation, air temperature, relative humidity, or wind speed does not change the RMSE by more than $0.7 \mathrm{~mm}$ compared with the standard model run (Table 4). Only increasing the outgoing longwave radiation by $5 \%$ causes a marked change to the RMSE (RMSE $=87.8 \mathrm{~mm}$ ). Increasing the outgoing longwave radiation by $5 \%$ causes an increase of sublimation of $26 \%$, but more significantly, it causes an increase in total melt of $377 \%$ compared with the original model run due to the increase in surface temperature calculated from outgoing longwave measurements. These results further stress the importance of using appropriate parameterizations of surface temperature on cold glacier surfaces.

Errors can also be caused by the selection of fixed parameters within the model, especially in the calculation of the turbulent heat fluxes. As the turbulent heat fluxes, specifi-

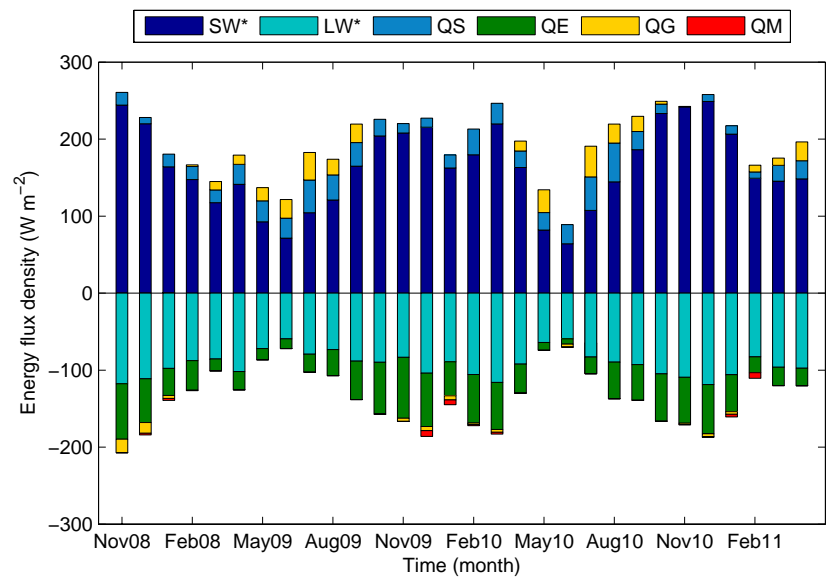

Fig. 5. Monthly averages of the modelled heat fluxes at the Guanaco Glacier surface for the period 9 October 2008-30 April 2011. (Note: $\mathrm{SW}^{*}$ is net shortwave radiation, $\mathrm{LW}^{*}$ is net longwave radiation, QS is the sensible heat flux, QL is the latent heat flux, QG is the subsurface heat flux, and QM is the energy consumed by melt).

cally the latent heat flux, have been shown to play an important role in the surface energy balance on Guanaco Glacier (Fig. 4) it is vital that we test the sensitivity to model parameters. The model was run using a stability correction based on the Richardson number (standard run), and without the stability correction (stability - off; Table 4). From this analysis it appears that the use of a stability function does not significantly alter the modelled result (RMSE $6.8 \mathrm{~mm}$ ). Additionally, the difference in calculated melt between the run with and without using the stability function is small $(-3 \%$ change), as is the impact on sublimation and net ablation (8\% and $6 \%$ changes, respectively). This small impact is not surprising as it has been shown that meteorological conditions in similar environments only cause slight fluctuations around near-neutral stability (e.g. Fig. 6 in Mölg and Hardy, 2004). 
Table 4. Sensitivity analysis undertaken for several model variables. The uncorrected longwave radiation is tested; the other variations to the meteorological input data (i.e. shortwave radiation, longwave radiation, air temperature, relative humidity, wind speed, albedo) are based on the instrument precision; and the roughness length change is based on standard sensitivity tests run in other glacier energy balance studies (e.g. Giesen et al., 2008). The RMSE and bias results compare the respective model result with measurements of surface lowering.

\begin{tabular}{|c|c|c|c|c|c|c|c|c|c|c|c|c|c|}
\hline \multirow[t]{2}{*}{ Parameter changed } & & \multicolumn{3}{|c|}{ Sublimation } & \multicolumn{3}{|c|}{ Melt } & \multicolumn{3}{|c|}{ Net ablation } & \multirow{2}{*}{$\begin{array}{r}\text { Melt } \\
\text { fraction of } \\
\text { net ablation } \\
(\%)\end{array}$} & \multirow{2}{*}{$\begin{array}{l}\text { RMSE } \\
\text { (mm) }\end{array}$} & \multirow{2}{*}{$\begin{array}{l}\text { Bias } \\
(\mathrm{mm})\end{array}$} \\
\hline & & Sum & $\Delta$ & $\% \Delta$ & Sum & $\Delta$ & $\% \Delta$ & Sum & $\Delta$ & $\% \Delta$ & & & \\
\hline Original & & 1164 & & & & & & 1435 & & & 19 & 4.1 & 0.6 \\
\hline Uncorrected LW & & 1208 & 44 & 4 & 799 & 528 & 195 & 2007 & 572 & 40 & 40 & 36.5 & 32.5 \\
\hline \multirow[t]{2}{*}{ SWI } & $-5 \%$ & 1163 & -1 & 0 & 242 & -29 & -11 & 1405 & -30 & -2 & 17 & 4.2 & -1.0 \\
\hline & $+5 \%$ & 1165 & 1 & 0 & 299 & 28 & 10 & 1464 & 29 & 2 & 20 & 4.8 & 2.1 \\
\hline \multirow[t]{2}{*}{ Albedo } & $-5 \%$ & 1165 & 1 & 0 & 298 & 27 & 10 & 1463 & 28 & 2 & 20 & 4.8 & 2.1 \\
\hline & $+5 \%$ & 1163 & -1 & 0 & 244 & -27 & -10 & 1407 & -28 & -2 & 17 & 4.2 & -0.9 \\
\hline \multirow[t]{2}{*}{ LWI } & $-5 \%$ & 1164 & 0 & 0 & 259 & -12 & -4 & 1423 & -12 & -1 & 18 & 4.1 & -0.1 \\
\hline & $+5 \%$ & 1165 & 1 & 0 & 282 & 11 & 4 & 1447 & 12 & 1 & 19 & 4.3 & 1.2 \\
\hline \multirow[t]{2}{*}{ LWO } & $-5 \%$ & 1130 & -34 & -3 & 205 & -66 & -24 & 1335 & -100 & -7 & 15 & 6.8 & -4.6 \\
\hline & $+5 \%$ & 1471 & 307 & 26 & 1293 & 1022 & 377 & 2764 & 1329 & 93 & 47 & 87.8 & 75.8 \\
\hline \multirow[t]{2}{*}{ Air temperature } & $-0.2^{\circ}$ & 1171 & 7 & 1 & 270 & -1 & 0 & 1441 & 6 & 0 & 19 & 4.1 & 0.8 \\
\hline & $+0.2^{\circ}$ & 1157 & -7 & -1 & 272 & 1 & 0 & 1429 & -6 & 0 & 19 & 4.1 & 0.3 \\
\hline \multirow[t]{2}{*}{ Relative humidity } & $-2 \%$ & 1185 & 21 & 2 & 269 & -2 & -1 & 1454 & 19 & 1 & 19 & 4.5 & 2.0 \\
\hline & $+2 \%$ & 1144 & -20 & -2 & 273 & 2 & 1 & 1417 & -18 & -1 & 19 & 4.4 & -0.8 \\
\hline \multirow[t]{2}{*}{ Wind speed } & $-0.2 \mathrm{~m} \mathrm{~s}^{-1}$ & 1161 & -3 & 0 & 271 & 0 & 0 & 1432 & -3 & 0 & 19 & 4.1 & 0.4 \\
\hline & $+0.2 \mathrm{~m} \mathrm{~s}^{-1}$ & 1196 & 32 & 3 & 268 & -3 & -1 & 1464 & 29 & 2 & 18 & 4.6 & 2.2 \\
\hline \multirow[t]{2}{*}{$z_{0 \mathrm{~h}}$} & $0.1 \mathrm{x}$ & 958 & -206 & -18 & 288 & 17 & 6 & 1246 & -189 & -13 & 23 & 12.7 & -10.0 \\
\hline & $10 \mathrm{x}$ & 1494 & 330 & 28 & 247 & -24 & -9 & 1741 & 306 & 21 & 14 & 20.4 & 18.0 \\
\hline \multirow{2}{*}{$z_{0 \mathrm{~m}}$} & $0.1 \mathrm{x}$ & 912 & -252 & -22 & 291 & 20 & 7 & 1203 & -232 & -16 & 24 & 15.3 & -12.3 \\
\hline & $10 \mathrm{x}$ & 1629 & 465 & 40 & 237 & -34 & -13 & 1866 & 431 & 30 & 13 & 28.5 & 24.6 \\
\hline Stability & Off & 1253 & 89 & 8 & 264 & -7 & -3 & 1517 & 82 & 6 & 17 & 6.5 & 4.9 \\
\hline
\end{tabular}

The specification of roughness lengths can be problematic, as they can be highly variable over space and time (Brock et al., 2006). As roughness lengths are difficult to measure, values are often taken from published literature (e.g. Mölg and Hardy, 2004), or are used as tuning parameters to fit the measured ablation results (e.g. Hoffman et al., 2008). In this study, the roughness lengths were selected from short-term unpublished eddy covariance measurements in the case of ice surfaces, and from published literature in the case of snow surfaces (Mölg et al., 2009). To determine the range of error involved with modifying the roughness lengths, the values for the roughness length of momentum, and the roughness length of heat/vapour were altered by an order of magnitude (each separately) (Table 4). Decreasing the roughness length of momentum by an order of magnitude produced decreases of sublimation and net ablation values larger than $15 \%$ compared to the original model results. Comparatively, increasing the roughness length of momentum caused an increase of $40 \%$ of sublimation, but decreased melt by $13 \%$. Increasing or decreasing the roughness length of heat/vapour caused less than a $10 \%$ change in melt, but larger changes in sublimation totals. Decreasing (increasing) the roughness length of heat/vapour by an order of magnitude caused an $18 \%$ decrease (28\% increase) in sublimation. These results suggest that the selection of roughness lengths in this environment needs to be undertaken in a well-considered manner. However, none of the variations in meteorological input variables or model parameters change the general ablation characteristics.

\section{Discussion}

\subsection{Comparison of ablation results with other studies}

The fraction of net ablation caused by melt is much smaller than that generally calculated for temperate and maritime glaciers (Table 3; Fig. 5; e.g. Giesen et al., 2008; Gillet and Cullen, 2011). However, they are within the range of rates and ratios recorded in arid high-altitude or polar environments (e.g. Kull et al., 2002; Mölg et al., 2008; Hoffman et al., 2008).

As was previously found for other glaciers in the semiarid Andes of Chile (Kull et al., 2002), sublimation is the dominant ablation process on the upper Guanaco Glacier (Table 3). At Guanaco Glacier, average daily sublimation rates calculated across the study period (mean $1.3 \mathrm{~mm}$ w.e. $\mathrm{d}^{-1}$ ) were inline with those estimated in other studies in the region (e.g. Ginot et al., 2001). An intensive study at the summit of Tapado Glacier, a valley glacier to the south of Guanaco Glacier $\left(30^{\circ} 08^{\prime} \mathrm{S}\right.$, $5500 \mathrm{~m}$ a.s.1.) found that melt was 
insignificant and that sublimation was the dominant form of ablation. Sublimation accounted for losses of $46 \%$ of the total estimated precipitation at the summit for the period 1962-1999 at a rate of $0.9 \mathrm{~mm}$ w.e. $\mathrm{d}^{-1}$ (Ginot et al., 2006). Rates were also measured and modelled for a six-day period during February 1999, and values ranged between 1.31.9 mm w.e. $\mathrm{d}^{-1}$ (Ginot et al., 2001; Kull and Grosjean, 2000; Kull et al., 2002). As rates in February are likely to be among the highest occurring throughout the year, it is likely that the mean annual sublimation rate lies between $0.9-1.3 \mathrm{~mm}$ w.e. This means that the rate experienced at Guanaco Glacier throughout the year is at the upper limit lower of that calculated for the upper Tapado Glacier.

Comparisons of sublimation and melt rates can also be made with high-altitude glaciers from tropical regions (e.g. Wagnon et al., 1999a, b; Sicart et al., 2005; Mölg et al., 2008, 2009). The striking difference between the energy balance regimes on these glaciers with Guanaco Glacier is the seasonality of signal. In the tropics, traditional winter-summer patterns are replaced with dry-wet season regimes. This means that ablation behaviour is often dictated more by albedo changes driven by precipitation and humidity changes, than by the annual progression of incoming shortwave radiation, as experienced in sub-tropical regions (e.g. Wagnon et al., 1999a). As on Guanaco Glacier, all studied glaciers in the tropics experience sublimation, and often record intermittent melt. However, the tropical glaciers usually experience a higher melt fraction than that calculated for Guanaco Glacier (e.g. Mölg et al., 2008, 2009), and sublimation is less important during the wet season (e.g. Wagnon et al., 1999a, b; Winkler et al., 2009), whereas the importance of sublimation is relatively constant throughout the year at Guanaco Glacier, even though the rate may change (Fig. 5).

Continuous sublimation rates, and episodic surface melting has also been described on glaciers in the McMurdo Dry Valleys, Antarctica (e.g. Lewis et al., 1998; Hoffman et al., 2008; MacDonell et al., 2012). Surface energy balance studies have all shown the dominance of sublimation on ice surfaces in this region, and have intimated that not only is melt restricted to approximately two months in the austral summer, but within this period, melting is episodic and spatially constrained (Lewis et al., 1998; Hoffman et al., 2008). Melt at the surface is often restricted to areas where albedo is lowered due to the incorporation of sediment (e.g. MacDonell et al., 2012), or to where wind speeds are reduced by topographic features (e.g. Johnston et al., 2005). Conditions conducive to sublimation are the main limiting factors of surface melt in this environment (Hoffman et al., 2008), and the only time when significant melt events on glacier surfaces have been recorded is during prolonged "high" temperature events (e.g. Doran et al., 2008).

\subsection{Meteorological conditions driving sublimation processes}

Results from the correlation analysis (Table 5) between raw daily sublimation and meteorological variables, i.e. before removing the seasonal cycle, highlights the seasonal nature of the sublimation-driven ablation on upper Guanaco glacier. The daily sublimation rate is most strongly correlated with net shortwave radiation $(r=0.75)$, which is mainly driven by the seasonal cycle of incoming shortwave radiation $(r=$ $0.61)$ and partly by the varying albedo $(r=-0.57)$. The albedo shows only a weak seasonal signal, as snow deposition at the AWS is irregular and episodic throughout the year (Fig. 2). A decreasing albedo augments the absorption of solar radiation at the surface, and it also implies an increased roughness length due to snow aging and ice exposition, which further promotes sublimation. Hence on a seasonal basis, sublimation increases during summer under strong incoming solar radiation and tends to decrease during episodic albedo rises throughout the year.

The correlation using detrended data reveals sub-seasonal meteorological forcing of sublimation. Day-to-day changes (i.e. detrended series) in vapour pressure $(r=-0.57)$ and wind speed $(r=0.39)$ are significantly correlated with sublimation. Hence, as expected, drier and windier weather enhance sublimation. As at the seasonal scale, sublimation is positively correlated with the net solar radiation $(r=0.56)$ and inversely correlated with albedo $(r=-0.57)$, while a weaker correlation is found with the incoming solar radiation $(r=0.40)$. This means than at sub-seasonal timescale, dayto-day variations in incoming solar radiation are not the main driver of sublimation. Instead, day-to-day changes in surface albedo appear to be more important in driving sublimation at the event scale. The coefficient of variation $(\mathrm{CV})$ for the detrended albedo $(\mathrm{CV}=13.6)$ is much greater than that of the detrended incoming shortwave radiation $(\mathrm{CV}=2.5)$, which means that at a sub-seasonal scale the albedo is more important for driving the net solar radiation than are variations in incoming solar radiation. The episodic albedo rises, when associated with a snowfall, also imply a decrease in roughness length and hence of sublimation. The negative correlation found with incoming longwave radiation $(r=-0.35)$ and cloud cover $(r=-0.33)$ reflect, to a lesser extent, the fact that overcast weather enhances incoming longwave radiation (MacDonell et al., 2013) and occurs with higher relative humidity, thus increasing vapour pressure and decreasing sublimation. As clouds have been found to significantly augment the albedo at this site (Abermann et al., 2013), and elsewhere (e.g. Jonsell et al., 2003), the negative correlation between albedo and sublimation must partly reflect the effect of clouds, and the lower correlation between sublimation and snowfall $(r=-0.22)$ tends to confirm this. A negative correlation with the east-west component of the wind ( $u$-wind, $r=0.33$ ) implies that sublimation is somewhat enhanced when the wind originates from a more westerly direction. In 
Table 5. Correlation coefficient $(r)$ between daily sublimation $\left(\mathrm{mm}\right.$ w.e. day $^{-1}$ ) and principal meteorological variables recorded at the AWS. $r_{\text {detrended }}$ is the correlation coefficient using detrended data, i.e. after removing the seasonal cycle for each variable except the cloud cover and snowfall, which are bounded by zero. The $5 \%$ significance level determined from the permutation test is indicated in parenthesis and significant correlations are indicated in bold. Variables are ordered from the largest to smallest $r_{\text {detrended }}$ absolute value.

\begin{tabular}{lrr}
\hline Variable & $r$ & $r_{\text {detrended }}$ \\
\hline Vapour pressure & $-\mathbf{0 . 3 2}(-0.23)$ & $-\mathbf{0 . 5 7}(-0.14)$ \\
Albedo & $-\mathbf{0 . 5 7}(-0.22)$ & $-\mathbf{0 . 5 7}(-0.1)$ \\
SW $^{*}$ & $\mathbf{0 . 7 5}(0.24)$ & $\mathbf{0 . 5 6}(0.12)$ \\
SWI & $\mathbf{0 . 6 1}(0.24)$ & $\mathbf{0 . 4}(0.1)$ \\
Wind speed & $\mathbf{0 . 1 7}(0.16)$ & $\mathbf{0 . 3 9}(0.09)$ \\
LWI & $-\mathbf{0 . 3 6}(-0.14)$ & $-\mathbf{0 . 3 5}(-0.11)$ \\
Cloud cover & $-\mathbf{0 . 4 8}(-0.15)$ & $-\mathbf{0 . 3 2}(-0.13)$ \\
Snowfall & $-\mathbf{0 . 2 9}(-0.09)$ & $-\mathbf{0 . 2 2}(-0.08)$ \\
Air temperature & $\mathbf{0 . 2 6}(0.23)$ & $\mathbf{0 . 1 6}(0.1)$ \\
\hline
\end{tabular}

summary, the correlation analysis shows that on a seasonal scale, sublimation is driven by the energy available at the surface, which is dominated by the seasonal cycle in incoming solar radiation and by more episodic changes in albedo. At the event scale, i.e., after removing the seasonal cycle in the data, variations in the net solar radiation, predominantly driven by episodic albedo variations, as well as air humidity variability, mainly drive the sublimation rates. Dry, windy and clear weather conditions are the most favourable for high sublimation rates.

\subsection{Meteorological processes controlling surface melting}

Surface melting is rare on upper Guanaco glacier, and as such, modelled melt follows an extreme value distribution that is poorly suited to linear correlation analysis as was used for sublimation. Moreover, because Guanaco is a cold glacier, the triggering of surface melting may also depend on preconditioning. The AWS on the high and exposed upper Guanaco glacier probably samples amongst the most extreme meteorological conditions found in the area, which makes it interesting to understand when, and how, melting occurs here.

The mean diurnal energy balance cycle for days with modelled melt shows increased daytime contribution of net solar radiation $\left(\mathrm{SW}^{*}\right.$, Fig. 6a) while the net longwave radiation diurnal cycle remains essentially unchanged (Fig. 6b). However, daytime differences in $\mathrm{SW}^{*}$ are only significant from 13:00 onward, i.e. shortly after solar noon. Closer inspection revealed that higher afternoon incoming solar radiation (SWI) is responsible for the higher $\mathrm{SW}^{*}$, while the albedo does not show clear differences. Differences in $\mathrm{SW}^{*}$ appear to be driven by a slightly decreased incidence of afternoon
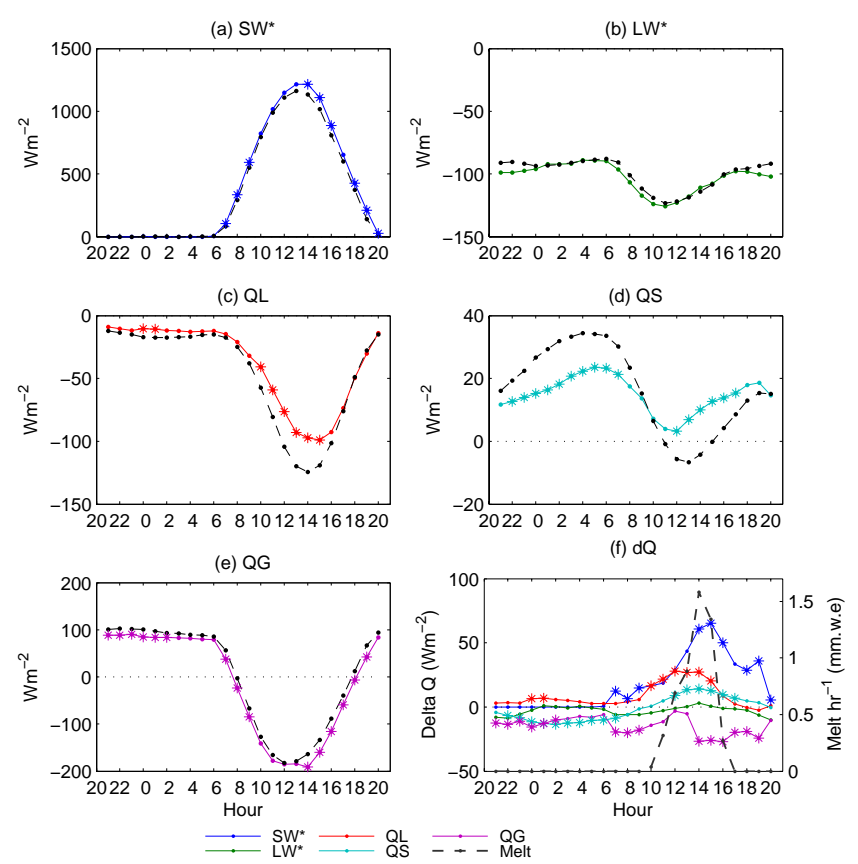

Fig. 6. Mean diurnal cycle of the surface energy fluxes $(Q)$ on the upper Guanaco glacier during summer for days with melting (coloured lines) and days without melting (black lines). (a) Net shortwave radiation flux; (b) net longwave radiation flux; (c) turbulent latent heat flux; (d) sensible heat flux; (e) total ground heat flux; (f) difference between melt and non-melt days (colour lines, left axis), and mean hourly melting rate (black dotted line, right axis).

convective clouds, typical of summer in this area, and as measured by an effective cloud cover index ( $n_{\text {eff }}$, MacDonell et al., 2013). A correlation of $r=-0.98$ between the SWI difference and the cloud cover index difference between melt and non-melt days corroborates this conclusion. However the low cloud cover for both melt and non-melt days $\left(n_{\mathrm{eff}}<\right.$ $0.15)$ reflect the predominant clear skies during summer and as the difference between melt and non-melt cloud cover is not statistically significant, the exact cause for increased SWI and $\mathrm{SW}^{*}$ remains uncertain. Latent heat loss (QL) by turbulence is appreciably lower on melt days compared to nonmelt days, mostly from the morning to mid-afternoon when differences are statistically significant (Fig. 6c). The diurnal sensible heat flux is smaller compared to non-melt summer days and also remains positive throughout the day, with most hours showing a significant difference (Fig. 6d). The attenuation occurs in part because the fixed temperature of the melting surface $\left(T_{\mathrm{s}}=273.15 \mathrm{~K}\right)$ reduces temperature gradients between the surface and the atmosphere. The total subsurface heat flux (QG), consisting of the sum of QC and QPS, is reduced throughout the whole diurnal cycle (Fig. 6e). The mean relative contribution of the individual energy fluxes to melting is shown Fig. 6f. The enhanced energy gain during daytime is due, in order of relative importance, to increased 
net solar radiation $\left(\mathrm{SW}^{*}\right)$, decreased QL loss (reduced sublimation), and a slight increase in the sensible heat flux (QS). On the other hand, a slight decrease in QG and QS is observed on nights prior to melting days. The higher energy input during melting days is used to melt the surface with a mean maximum rate of $1.6 \mathrm{~mm} \mathrm{~h}^{-1}$ (Fig. $6 \mathrm{f}$, right axis). The mean modelled subsurface temperature profile (Fig. 7) shows that nighttime cooling is less pronounced during melt days than during non-melt days. During melt days the glacier surface layers heat up rapidly, quickly removing the nighttime cold wave and allowing the surface to reach the melting point typically at midday. The difference in subsurface temperatures shows an upward warming trend during melt days (Fig. 7c), which indicates a smoother near-surface temperature gradient and reduced upward heat conduction (QC) at night, and a steeper gradient and increased downward heat conduction during daytime (Fig. 6e). Increased penetration of solar radiation during the day (QPS, not shown), due to the higher $\mathrm{SW}^{*}$ on melt days, also explains part of the more negative glacier heat flux (QG) between 12:00 and 16:00 (Fig. 6e). Calculating melt rates can also be challenging due to the prevalence of melt below the surface caused by radiative heating (Brandt and Warren, 1993; Hoffman et al., 2008). Unless absorbed shortwave radiation is removed quickly via conduction into the ice body, the subsurface ice may begin to melt, even if the surface temperature is below freezing. The modelled subsurface temperature occasionally reached the melting point within the first metre, which suggests that subsurface melting may occur at the site, and so that total runoff from the AWS site may be underestimated.

The surface energy balance represents the direct link between the weather and the glacier mass-balance. Prevailing meteorological conditions recorded at the AWS during days with melting show on average about $4{ }^{\circ} \mathrm{C}$ higher temperatures (Fig. 8a), with air temperatures reaching above $0{ }^{\circ} \mathrm{C}$ from 11:00 $\mathrm{h}$ to 17:00 $\mathrm{h}$. This allows for a positive sensible heat flux to the glacier surface during this time, as the surface is near or at $0^{\circ} \mathrm{C}$. The vapour pressure (Fig. 8b) is also noticeably higher, while the wind speed is much reduced (Fig. 8d) during days with melting, which explains the reduced sublimation rates (or for hours when the surface melts, reduced evaporation) and the excess energy available for warming and melting the surface. These warmer, more humid and calm weather conditions occur under high-pressure systems (Fig. 8c). The wind direction, (Fig. 8e) shows a slight deflection south of the predominant northwest flow in the morning, but overall there is not a strong directional discrepancy of air flow between days with and without melting.

In conclusion, the prevailing cold, dry and windy weather conditions on the upper Guanaco glacier promote large sublimation losses which dominate ablation. The high solar radiation, low vapour pressure and the strong winds, which increase turbulence and drive upward moisture transport, both favour sublimation. The frequently exposed ice surface, by augmenting the aerodynamic roughness, also further pro-
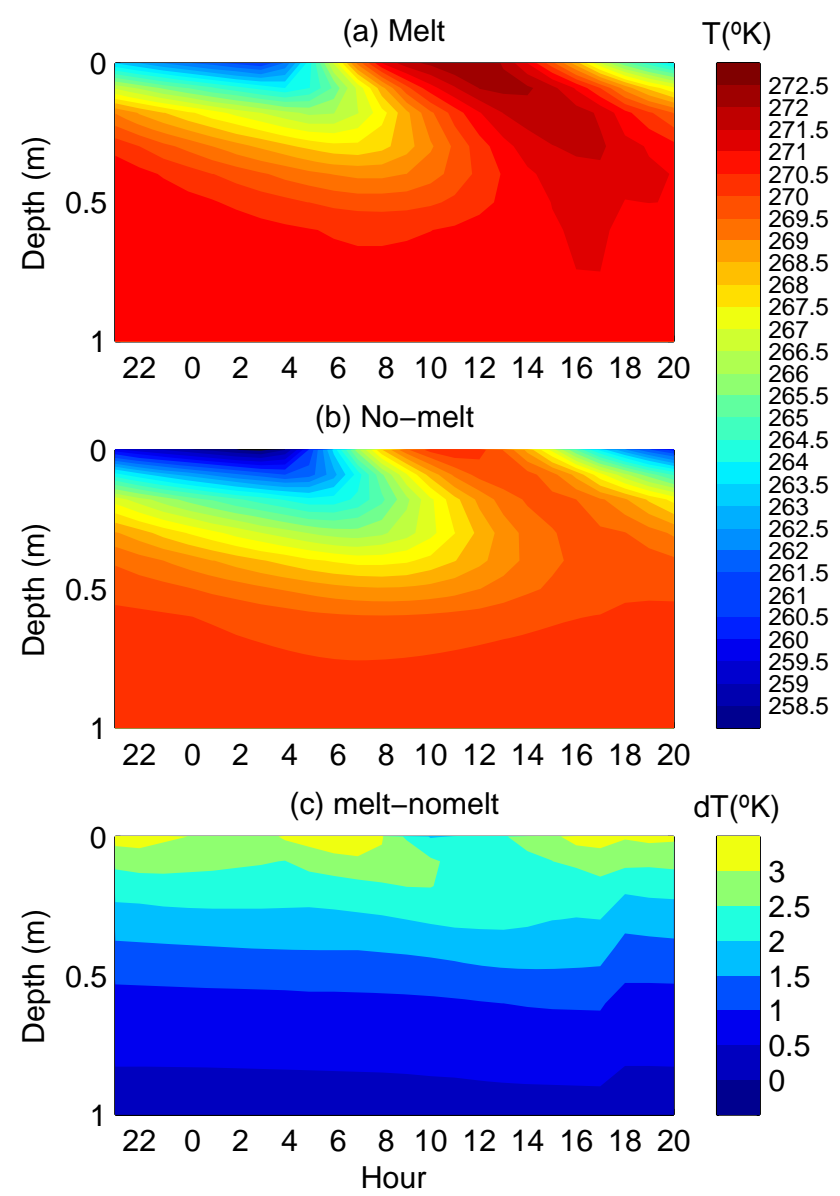

Fig. 7. Mean diurnal cycles of surface and subsurface temperatures for (a) days with melting; (b) summer days without melting; (c) melt minus non-melt days.

motes sublimation losses. High-pressure systems in summer bring occasional breaks to these extreme conditions, allowing the glacier surface to warm and melt for a few hours in the afternoon. The clear weather associated with the higher air pressure increases the incoming solar radiation, which is the main energy source for warming the glacier surface in the morning and melting in the afternoon. However, the low wind speed and higher vapour pressure, by reducing sublimation, is also instrumental in making more energy available for surface melting, as is the day time air temperature above $0^{\circ} \mathrm{C}$, which drive a positive sensible heat flux to the melting surface.

\section{Conclusions}

This study represents the first energy balance calculation made in the Norte Chico region of Chile, which constitutes an environment that is both high (5324 m a.s.1.) and very dry (vapour pressure annual average of $1.1 \mathrm{hPa}$ ). The extreme aridity of the location mean that the energy balance most 

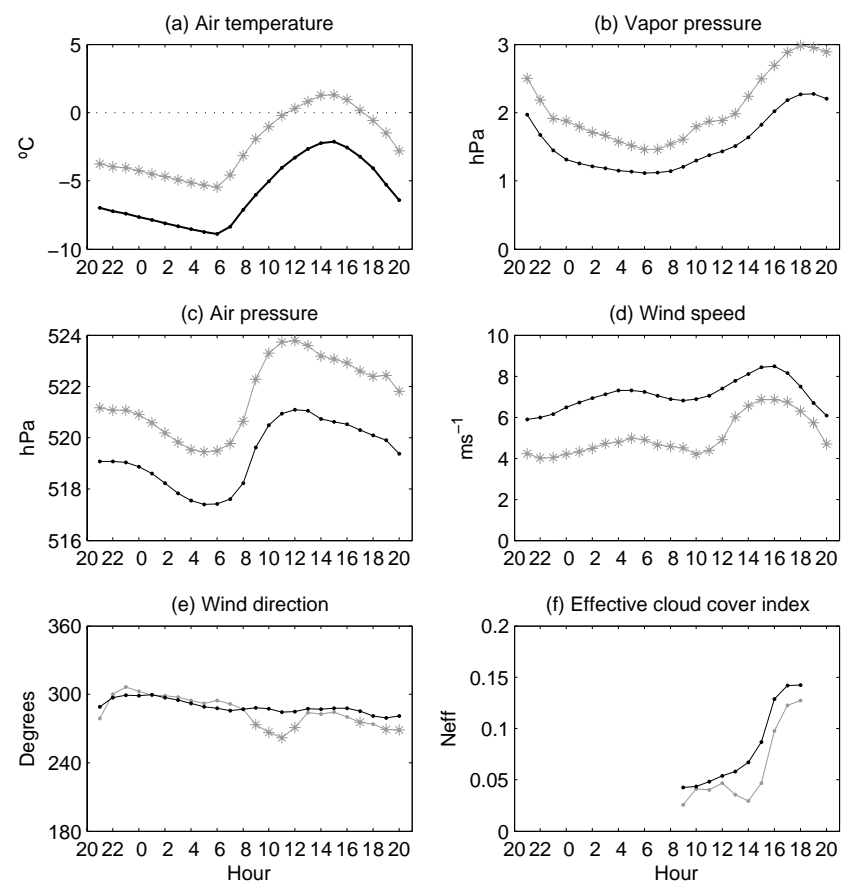

Fig. 8. Mean diurnal cycle in meteorological conditions for days with melt (grey line) and days without melt (black lines). Wind direction is calculated from the mean $u, v$ orthogonal components. Hours during which melt days are statistically different than nonmelt days $(p<0.05)$ are indicated by an asterisk. The same permutation test used for energy fluxes was used.

closely resembles those reported in the McMurdo Dry Valleys, Antarctica (e.g. Hoffman et al., 2008; MacDonell et al., 2012), and in high-altitude tropical regions (e.g. Mölg et al., 2008; Winkler et al., 2009).

The studied site on the Guanaco Glacier has a net loss between 1 November 2008 and 30 April 2011, which follows the trend outlined in Rabatel et al. (2011). Modelled ablation is dominated by sublimation, however episodic melting occurs. Sublimation is most strongly related to net shortwave radiation, incoming shortwave radiation, albedo and vapour pressure. Sublimation represents a dominant control on melting. That is, melt only occurs when energy used by sublimation (i.e. the turbulent latent heat flux) is relatively small, which is when relative humidity is relatively high and the wind speed is low. Melt days are restricted to the summer, and to relatively warm, humid, calm conditions with high air pressure relative to non-melt days.

Sensitivity analyses show that ablation is sensitive to changes in surface temperature and roughness lengths, which suggests that these properties need to be well constrained for successful energy balance modelling on glaciers in this area. Modelled ablation is sensitive to the surface temperature used in the calculation as the measured temperature is often close to, but not at the melting point. This has important implications both for parameterizing surface tempera- ture, using measurements and for understanding possible future changes in the surface energy balance at this site.

Accurately determining roughness lengths is especially important when considering distributed modelling of energy balance processes over glaciers in this region as surfaces are generally heterogeneous, with penitente coverage varying both in space and time. As penitentes form in the lower reaches of the Guanaco Glacier, the energy balance calculated here is unlikely to be representative of the glacier as a whole, but is likely to well-represent the upper reaches where penitentes are not found, and melt is rarely observed.

This study is a first step in understanding glacier contribution to streamflow in the semi-arid Andes of Chile. Further distributed modelling is needed to assess glacier contribution to runoff for whole catchments, which requires accurate modelling of planar and penitente-covered surfaces. However, in order to achieve this aim, an understanding of the effect of penitentes on surface roughness is required. Additionally, as glaciers represent only one source of water to the catchment, more detailed models of snow processes such as that by Gascoin et al. (2012) are also recommended.

Acknowledgements. S. MacDonell was supported by FONDECYT Postdoctoral grant No. 3110053. We also thank the Barrick Gold Corporation for logistical support of this study as part of a glacier monitoring project in the semi-arid Andes, and the glaciology group at CEAZA for help in the field and the AWS installation. We are grateful for helpful comments from J. Corripio, the two anonymous reviewers and the handling editor V. Radić.

Edited by: V. Radic

\section{References}

Abermann, J., Kinnard, C., and MacDonell, S. Albedo variations of glacier surfaces in the Chilean Dry Andes, submitted, 2013.

Bintanja, R.:. On the glaciological, meteorological, and climatological significance of Antarctic blue ice areas, Rev. Geophys., 37, 337-359, 1999.

Bintanja, R. and van den Broeke, M. R.: The surface energy balance of Antarctic snow and blue ice, J. Appl. Meteorol., 34, 902-926, 1995.

Brandt, R. E. and Warren, S. G.: Solar heating rates and temperature profiles in Antarctic snow and ice, J. Glaciol., 39, 99-110, 1993.

Brock, B. W., Willis, I. C., and Sharp, M. J.: Measurement and parameterization of surface roughness variations at Haut Glacier d'Arolla, Switzerland, J. Glaciol., 52, 281-297, 2006.

Corripio, J. G. and Purves, R. S.: Surface energy balance of high altitude glaciers in the central Andes: The effect of snow penitentes, in Climate and Hydrology in Mountain Areas, edited by: de Jong, C., Collins, D., and Ranzi, R., John Wiley, London, 1527,2005

Cuffey, K. M. and Paterson, W. S. B.: The Physics of Glaciers, fourth edition, Elsevier, Oxford, 2010. 
Cullen, N. J., Mölg, T., Kaser, G., Steffen, K., and Hardy, D.: Energy-balance model validation on the top of Kilimanjaro, Tanzania, using eddy covariance data, Ann. Glaciol. 46, 227-233, 2007.

Davison, A. and Hinkley, D.: Bootstrap methods and their application, Cambridge University Press, Cambridge, 1997.

Doran, P. T., McKay, C. P., Fountain, A. G., Nylen, T., McKnight, D. M., Jaros, C., and Barrett, J. E.: Hydrologic response to extreme warm and cold summers in the McMurdo Dry Valleys, East Antarctica, Antarct. Sci., 20, 499-509, 2008.

Favier, V., Falvey, M., Rabatel, A., Praderio, E., and López, D.: Interpreting discrepancies between discharge and precipitation in high-altitude area of Chile's Norte Chico region (26-32 $\left.{ }^{\circ} \mathrm{S}\right)$, Water Resour. Res., 45, W02424, doi:10.1029/2008WR006802, 2009.

Gascoin, S., Kinnard, C., Ponce, R., Lhermitte, S., MacDonell, S., and Rabatel, A.: Glacier contribution to streamflow in two headwaters of the Huasco River, Dry Andes of Chile, The Cryosphere, 5, 1099-1113, doi:10.5194/tc-5-1099-2011, 2011.

Gascoin, S., Lhermitte, S., Kinnard, C., Borstel, K., and Liston, G. E.: Wind effects on snow cover in PascuaLama, Dry Andes of Chile, Adv. Water Resour., 55, 25-39, doi:10.1016/j.advwatres.2012.11.013, 2012.

Georges, C. and Kaser, G.: Ventilated and unventilated air temperature measurements for glacier-climate studies on a tropical high mountain site, J. Geophys. Res., 107, 4775, doi:10.1029/2002JD002503, 2002.

Giesen, R. H., van den Broeke, M. R., Oerlemans, J., and Andreassen, L. M.: Surface energy balance in the ablation zone of Midtdalsbreen, a glacier in southern Norway: Interannual variability and the effect of clouds, J. Geophys. Res., 113, D21111, doi:10.1029/2008JD010390, 2008.

Gillet, S. and Cullen, N.: Atmospheric controls on summer ablation over Brewster Glacier, New Zealand, Int. J. Climatol., 31, 2033 2048, 2011.

Ginot, P., Kull, C., Schwikowski, M., Schotterer, U., and Gäeggeler, H. W.: Effects of postdepositional processes on snow composition of a subtropical glacier (Cerro Tapado, Chilean Andes), J. Geophys. Res., 106, 32375-32386, 2001.

Ginot, P., Schwikowski, M., Schotterer, U., Stichler, W., Gaggeler, H. W., Francou, B., Gallaire, R., and Pouyaud, B.: Potential for climate variability reconstruction from Andean glaciochemical records, Ann. Glaciol., 35, 443-450, 2002.

Ginot, P., Kull, C., Schotterer, U., Schwikowski, M., and Gäggeler, H. W.: Glacier mass balance reconstruction by sublimation induced enrichment of chemical species on Cerro Tapado (Chilean Andes), Clim. Past, 2, 21-30, doi:10.5194/cp-2-21-2006, 2006.

Hoffman, M. J., Fountain, A. G., and Liston, G. E.: Surface energy balance and melt thresholds over 11 years at Taylor Glacier, Antarctica, J. Geophys. Res., 113, F04014, doi:10.1029/2008JF001029, 2008.

Johnston, R. R., Fountain, A. G., and Nylen, T. H.: The origin of channels on lower Taylor Glacier, McMurdo Dry Valleys, Antarctica, and their implication for water runoff, Ann. Glaciol., 40, 1-7, 2005.

Jonsell, U., Hock, R., and Holmgren, B.: Spatial and temporal variations in albedo on Storglaciaren, Sweden, J. Glaciol., 49, 59-68, 2003.
Kipp \& Zonen: CNR1 net radiometer instruction manual version 0706, Kipp \& Zonen, Delft, The Netherlands, 2002.

Kull, C. and Grosjean, M.: Late Pleistocene climate conditions in the north Chilean Andes drawn from a climate-glacier model, J. Glaciol., 46, 622-632, 2000.

Kull, C., Grosjean, M., and Veit, H.: Modeling modern and late Pleistocene Glacio-climatological conditions in the north Chilean Andes (29-30 S), Clim. Change, 52, 359-381, 2002.

Lewis, K. J., Fountain, A. G., and Dana, G. L.: Surface energy balance and meltwater production for a Dry Valley glacier, Taylor Valley, Antarctica, Ann. Glaciol., 27, 603-609, 1998.

MacDonell, S., Nicholson, L., and Kinnard, C.: Parameterisation of incoming longwave radiation over glacier surfaces in the semiarid Andes of Chile, Theor. Appl. Climatol., 111, 513-528, 2013.

MacDonell, S. A., Fitzsimons, S. J., and Mölg, T.: Seasonal sediment fluxes forcing supraglacial melting on the Wright Lower Glacier, McMurdo Dry Valleys, Antarctica, Hydrol. Process., doi:10.1002/hyp.9444, 2012.

Michel, D., Philipona, R., Ruckstuhl, C., Vogt, R., and Vuilleumier, L.: Performance and uncertainty of CNR1 Net Radiometers during a one-year field campaign, J. Atmos. Ocean. Technol., 25, 442-451, 2008

Mölg, T. and Hardy D. R.: Ablation and associated energy balance of a horizontal glacier surface on Kilimanjaro, J. Geophys. Res. 109, D16104, doi:10.1029/2003JD004338, 2004.

Mölg, T., Cullen, N., Hardy, D. R., Kaser, G., and Klok, L.: Mass balance of a slope glacier on Kilimanjaro and its sensitivity to climate, Int. J. Climatol., 28, 881-892, 2008.

Mölg, T., Cullen, N. J., Hardy, D. R., Winkler, M., and Kaser, G. Quantifying climate change in the tropical midtroposphere over East Africa from glacier shrinkage on Kilimanjaro, J. Climate, 22, 4162-4181, 2009.

Murray, F. W.: On the computation of saturation vapor pressure, J Appl. Meteorol., 6, 203-204, 1967.

Nash, J. E. and Sutcliffe, J. V.: River flow forecasting through conceptual models. Part I - A discussion of principles, J. Hydrol., 10, 282-290, 1970

Nicholson, L., Marín, J., Lopez, D., Rabatel, A., Bown, F., and Rivera, A.: Glacier inventory of the upper Huasco valley, Norte Chico, Chile: glacier characteristics, glacier change and comparison with central Chile, Ann. Glaciol., 50, 111-118, 2010.

Obleitner, F. and De Wolde, J.: On intercomparison of instruments used within the Vatnajökull glacio-meteorological experiment, Bound.-Lay. Meteorol., 92, 25-35, 1999.

Rabatel, A., Castebrunet, H., Favier, V., Nicholson, L., and Kinnard, C.: Glacier changes in the Pascua-Lama region, Chilean Andes $\left(29^{\circ} \mathrm{S}\right)$ : recent mass balance and $50 \mathrm{yr}$ surface area variations, The Cryosphere, 5, 1029-1041, doi:10.5194/tc-5-10292011, 2011.

Sicart, J. E., Wagnon, P., and Ribstein, P.: Atmospheric controls of the heat balance of Zongo Glacier ( $16^{\circ} \mathrm{S}$, Bolivia), J. Geophys. Res., 110, D12106, doi:10.1029/2004JD005732, 2005.

Sonntag, D.: Important new values of the physical constants of 1986, vapor pressure formulations based on the ITC-90, and psychrometer formulae, Z. Meteorol., 40, 340-344, 1990.

van den Broeke, M. R., van As, D., Reijmer, C. H., and van de Wal, R. S. W.: Assessing and improving the quality of unattended radiation observations in Antarctica, J. Atmos. Ocean. Technol., 21, 1417-1431, 2004 
Wagnon, P., Ribstein, P., Francou, B., and Pouyaud, B.: Annual cycle of energy balance of Zongo Glacier, Cordillera Real, Bolivia, J. Geophys. Res., 104, 3907-3923, 1999a.

Wagnon, P., Ribstein, P., Kaser, G., and Berton, P.: Energy balance and runoff seasonality of a Bolivian glacier, Global Planet. Change, 22, 49-58, 1999b.
Wagnon, P., Sicart, J.-E., Berthier, E., and Chazarin, J.-P.: Wintertime high-altitude surface energy balance of a Bolivian glacier, Illimani, $6340 \mathrm{~m}$ above sea level, J. Geophys. Res., 108, 4177, doi:10.1029/2002JD002088, 2003.

Winkler, M., Juen, I., Mölg, T., Wagnon, P., Gómez, J., and Kaser, G.: Measured and modelled sublimation on the tropical Glaciar Artesonraju, Perú, The Cryosphere, 3, 21-30, doi:10.5194/tc-321-2009, 2009. 